\title{
The deleted in colorectal carcinoma (DCC) gene 201 $R \rightarrow G$ polymorphism: no evidence for genetic association with autoimmune disease
}

Richard J Hall ${ }^{1}$, Marilyn E Merriman ${ }^{1}$, Rachel A Green ${ }^{1}$, Valerie H Markham ${ }^{1}$, Deborah J Smyth ${ }^{2}$, Joanne M Heward ${ }^{3}$, Claire E Jennings ${ }^{4}$, Antony W Braithwaite ${ }^{5}$, Tim Cundy ${ }^{6}$, Brian A Darlow ${ }^{7}$, Peter J Gow ${ }^{8}$, Andrew A Harrison ${ }^{9}$, John Highton ${ }^{10}$, Penny J Hunt ${ }^{11}$, Patrick Manning ${ }^{12}$, Violetta Pokorny ${ }^{13}$, Russell S Scott ${ }^{14}$, Barry J Taylor ${ }^{15}$, Jinny A Willis ${ }^{14}$, Sue Yeoman ${ }^{16}$, Lachy McLean ${ }^{13}$, Stephen CL Gough ${ }^{3}$, Simon H Pearce and Tony R Merriman*,1

\footnotetext{
${ }^{1}$ Department of Biochemistry, University of Otago, Dunedin, New Zealand; ${ }^{2}$ Cambridge Institute for Medical Research, Addenbrooke's Hospital, UK; ${ }^{3}$ Department of Medicine, Birmingham Heartlands Hospital, UK; ${ }^{4}$ Institute of Human Genetics, University of Newcastle, UK; ${ }^{5}$ Department of Pathology, University of Otago, Dunedin, New Zealand; ${ }^{6}$ Department of Medicine, University of Auckland, New Zealand; ${ }^{7}$ Department of Paediatrics, Christchurch Hospital, New Zealand; ${ }^{8}$ Department of Rheumatology, Middlemore Hospital, Auckland, New Zealand; ${ }^{9}$ Wellington School of Medicine and Health Sciences, New Zealand; ${ }^{10}$ Department of Medicine, University of Otago, Dunedin, New Zealand; ${ }^{11}$ Department of Endocrinology, Christchurch Hospital, New Zealand; ${ }^{12}$ Department of Endocrinology, Dunedin Hospital, Dunedin, New Zealand; ${ }^{13}$ Department of Molecular Medicine, University of Auckland, New Zealand; ${ }^{14}$ Lipid and Diabetes Research Group, Christchurch Hospital, New Zealand; ${ }^{15}$ Department of Paediatrics, Dunedin Hospital, Dunedin, New Zealand; ${ }^{16}$ Department of Rheumatology, Auckland Hospital, New Zealand
}

The product of the deleted in colorectal carcinoma (DCC) gene has a role in apoptosis and is a positional candidate for IDDM6, the putative chromosome 18q12-q23 autoimmune disease locus. We hypothesised that a nonconservative substitution (DCC $201 \mathrm{R} \rightarrow \mathrm{G}$; nucleotide $(\mathrm{nt}) 601 \mathrm{C} \rightarrow \mathrm{G}$ ), located in an extracellular immunoglobulin-like domain of DCC, is an aetiological determinant of autoimmunity. We tested this hypothesis by genetically testing the nt $601 \mathrm{C} \rightarrow \mathrm{G}$ polymorphism for association with three autoimmune phenotypes in a large population-based case-control study. There was no evidence for association of $D C C$ nt $601 \mathrm{C} \rightarrow \mathrm{G}$ with autoimmune disease in cohorts comprising 2253 subjects with rheumatoid arthritis, type I diabetes and Graves' disease, and 2225 control subjects, from New Zealand and the United Kingdom. Furthermore, using the transmission disequilibrium test, there was no significant evidence for biased transmission of the nt $601 \mathrm{C} \rightarrow \mathrm{G}$ polymorphism to probands within a 382 family type I diabetes affected sibpair cohort from the United Kingdom. Thus, the DCC $201 \mathrm{R} \rightarrow \mathrm{G}$ polymorphism does not appreciably influence risk of developing the autoimmune diseases tested.

European Journal of Human Genetics (2003) 11, 840-844. doi:10.1038/sj.ejhg.5201059

Keywords: autoimmunity; polymorphism; DCC; IDDM6; genetic association

*Correspondence: $\mathrm{Dr} \mathrm{T}$ Merriman, Department of Biochemistry, University of Otago, Dunedin, New Zealand. Tel: +64 34795 798; Fax: + 6434797 866; E-mail: tony.merriman@stonebow.otago.ac.nz Received 18 February 2003; revised 29 April 2003; accepted 10 June 2003

\section{Introduction}

Genetic predisposition to autoimmune disease is universally associated with human leucocyte antigen class II alleles within the major histocompatibility complex (MHC) on chromosome $6 \mathrm{p} 21 .{ }^{1}$ However, genome-wide 
linkage scanning has implicated numerous other nonMHC regions in autoimmune disease susceptibility. ${ }^{2-10}$ One of these loci, the putative locus IDDM6 on chromosome $18 \mathrm{q} 12-\mathrm{q} 23$, has been linked to type I diabetes (T1D), rheumatoid arthritis (RA), Graves' disease (GD) and systemic lupus erythematosus. ${ }^{5-12}$ Meta-analysis provides evidence that the orthologous region in rodent (on distal chromosome 18 in mouse and rat) contains an autoimmune susceptibility locus ${ }^{11}$ with congenic mapping, proving that rat has a distal chromosome 18 diabetes locus $(\operatorname{Iddm} 3)^{13}$ and that mouse has a chromosome 18 diabetes locus (Idd21). ${ }^{14}$ Thus, there is considerable evidence to support linkage of chromosome 18q12-q23 and the rodent orthologous region to autoimmune phenotypes.

In humans, a study comprising 3380 families provided evidence for association with autoimmunity of a haplotype of two microsatellite markers within the IDDM6 positional candidate, the deleted in colorectal carcinoma (DCC) gene $\left(P=5 \times 10^{-6}\right) .{ }^{11}$ The DCC gene, a member of the immunoglobulin superfamily, encodes a receptor dependent on the ligand netrin-1. In the absence of netrin-1, DCC induces cell death through interaction with a membraneassociated adenosine A2b receptor. ${ }^{15-17}$ Cell death occurs via a cascade involving activation of caspase- 3 by caspase9 , independent of the mitochondrial and caspase-8/death receptor pathways. ${ }^{18}$ It is possible that DCC has uncharacterised role(s) in the regulation of central and/or peripheral tolerance to self-antigens or in abnormal apoptosis of cells targeted in autoimmunity.

The DCC gene has an exon 3 polymorphism $(601 \mathrm{C} \rightarrow \mathrm{G})$ that results in a codon $201 \mathrm{R} \rightarrow \mathrm{G}$ nonconservative substitution within the second of the four DCC extracellular Ig-like domains. ${ }^{19,20}$ We hypothesised that this substitution plays a role in the aetiology of autoimmune disease. There are strong a priori reasons to support the formulation of this hypothesis; evidence supporting linkage of the DCC region to human and rodent autoimmune phenotypes, ${ }^{5-12}$ association of the DCC gene with autoimmunity in humans, ${ }^{11}$ and the involvement of DCC in regulating apoptotic events. The hypothesis was tested by performing a population- and family-based study testing the genetic association of the DCC nucleotide (nt) $601 \mathrm{C} \rightarrow$ $G$ polymorphism with several autoimmune phenotypes (RA, T1D and GD).

\section{Materials and methods Subjects}

Type I diabetes cases $(n=354)$ were collected from the Auckland, Canterbury and Otago regions of New Zealand (NZ). The average and median ages at onset were 12.3 (range $<1-40$ years) and 11 years, respectively. All 671 RA cases were drawn from the Auckland, Bay of Plenty, Wellington, Otago and Southland regions of NZ, and satisfied the 1987 American College of Rheumatology criteria for disease. ${ }^{21}$ GD was defined by the presence of hyperthyroidism and diffuse goitre, supported by the presence of either thyroid antibodies (peroxidase and/or thyroglobulin) or thyroid-associated orbitopathy. The NZ GD cases $(n=180)$ were drawn from the Canterbury and Otago regions. All $1246 \mathrm{NZ}$ control subjects were healthy, over 17 years of age, and were drawn from the Otago region. The Birmingham GD cases $(n=731$, recruited from Birmingham, Bournemouth and Exeter, UK) and control subjects ( $n=668$, recruited within Birmingham) have been described previously. ${ }^{22}$ The Newcastle GD cases $(n=317)$ were recruited from Northern England and the Lothian region of Scotland. Healthy control subjects $(n=311)$ were recruited within Newcastle (UK). The 382 T1D UK affected sibpair families are described elsewhere. ${ }^{4}$ All case and control subjects and families were of white ethnicity. All subjects gave informed consent and the study was approved by the appropriate regional Ethics Committee.

\section{Genotyping}

The DCC nt $601 \mathrm{C} \rightarrow \mathrm{G}$ polymorphism was genotyped by a PCR-RFLP assay over the case and control subjects using primers $\left(5^{\prime} \rightarrow 3^{\prime}\right)$ ATTTGGAAGACTTATTCTTCC and CGGTAAATTCCAATGTCCCTCGGTTGGAGC. The second primer has a mismatch at the $3^{\prime}$ end (nt 603 of DCC), creating an MspI restriction site in the presence of $601 \mathrm{C}$. The nt $601 \mathrm{C} \rightarrow \mathrm{G}$ polymorphism was typed over the UK T1D families using Invader. ${ }^{23}$

\section{Power estimation}

We hypothesised that the autoimmune disease-associated 2-10 haplotype of DCC microsatellite markers 88,21 and 55,26 is in linkage disequilibrium with an aetiological polymorphism, namely DCC nt $601 \mathrm{C} \rightarrow \mathrm{G}$, that accounts for the previously observed association. ${ }^{11}$ The transmission ratio $(r)$ of this haplotype from heterozygous parents to affected offspring (0.547 in 2484 RA and T1D families), ${ }^{11}$ was used to estimate an odds ratio (OR) using the formula $r /(1-r)=1.21(95 \%$ confidence interval $(\mathrm{CI}) 1.12-1.31) .{ }^{24}$ Post priori power calculations were performed, as described, ${ }^{25}$ with the frequency of the DCC nt $601 \mathrm{G}$ (minor) allele estimated from the appropriate healthy control cohort. A post priori power calculation for the $\mathrm{TDT}^{26}$ was performed for the UK T1D affected sibpair family cohort using the OR estimated above and the DCC nt 601G allele frequency $(0.322)$ observed in parents.

\section{Results}

Previous reports of the frequency of the DCC nt $601 \mathrm{C} \rightarrow \mathrm{G}$ variant were from Japanese subjects $(601 \mathrm{G}$ frequency $=$ 0.56). ${ }^{19,27,28}$ To determine the allele frequency in white ethnic groups, $192 \mathrm{NZ}$ healthy control subjects were typed. The frequency of $601 \mathrm{G}$ was 0.35 . The relationship between DCC nt $601 \mathrm{C} \rightarrow \mathrm{G}$ and the 2-10 haplotype of 
Table 1 Association analysis of the DCC nt $601 \mathrm{C} \rightarrow \mathrm{G}$ polymorphism with autoimmune disease in NZ and UK case-control cohorts.

\begin{tabular}{llccccccrr}
\hline Phenotype & Origin & C & Cases & Freq & Controls & & Freq & $P^{\mathrm{b}}$ & Power (95\% CI) \\
\hline T1D & NZ & 454 & 254 & 0.359 & 1614 & 878 & 0.352 & 0.75 & $0.58(0.24-0.87)$ \\
RA & NZ & 864 & 478 & 0.356 & & & & 0.81 & $0.78(0.36-0.97)$ \\
GD & NZ & 234 & 126 & 0.350 & & & & 0.93 & $0.36(0.16-0.63)$ \\
T1D/RA/GD & NZ & 1552 & 858 & 0.356 & & & & 0.79 & $0.90(0.47-0.996)$ \\
GD (Birmingham) & UK & 938 & 524 & 0.358 & 863 & 473 & 0.354 & 0.81 & $0.68(0.30-0.93)$ \\
GD (Newcastle) & UK & 393 & 241 & 0.380 & 364 & 258 & 0.415 & 0.21 & $0.39(0.17-0.66)$ \\
\hline
\end{tabular}

NZ T1D/RA/GD, NZ control; Birmingham GD, Birmingham control; Newcastle GD and Newcastle control cohorts all exhibited Hardy-Weinberg equilibrium at DCC nt $601 \mathrm{C} \rightarrow \mathrm{G}$. ${ }^{\mathrm{a}}$ Frequency of the minor allele $\left(D C C\right.$ 601G, DCC 201G) is given. ${ }^{\mathrm{b}}$ The same control cohort was used in all four New Zealand comparisons. ${ }^{\mathrm{C}}$ The $\chi^{2}$ test (1 df) was used to compare DCC nt $601 \mathrm{C} \rightarrow \mathrm{G}$ allele frequency between case and control cohorts.

Table 2 Transmission of DCC [nt $601 \mathrm{C} \rightarrow \mathrm{G}]-[88,21]-$ $[55,26]$ haplotypes from heterozygous parents to probands in UK T1D affected sibpair families

\begin{tabular}{lrrrrr}
\hline Haplotype $^{\mathrm{a}}$ & $T$ & $N T$ & $\% T$ & $p^{\mathrm{b}}$ & Freq $^{\mathrm{c}}$ \\
\hline C-2-10 & 117 & 81 & 59.1 & 0.01 & 0.215 \\
C-2-11 & 61 & 45 & 57.5 & 0.12 & 0.103 \\
G-7-1 & 32 & 32 & 50.0 & 1.00 & 0.070 \\
C-2-12 & 41 & 25 & 62.1 & 0.05 & 0.060 \\
C-7-1 & 19 & 39 & 32.8 & 0.009 & 0.052 \\
G-2-10 & 12 & 20 & 37.5 & 0.16 & 0.034 \\
\hline
\end{tabular}

Transmission of multilocus haplotypes from heterozygous parents to offspring in the UK affected sibpair families was assessed using TDT phase software (http://www.hgmp.mrc.ac.uk). ${ }^{31}{ }^{a}$ Transmissions are shown for the five, and eighth most common, haplotypes. ${ }^{b} p$ calculated from the TDT statistic $\left(\chi^{2} 1 \mathrm{df}\right) .{ }^{32}{ }^{\text {c}}$ Frequency in parents. $\mathrm{T}=$ transmitted, $\mathrm{NT}=$ not transmitted, $\% \mathrm{~T}=$ percent transmission.

T1D-associated microsatellite markers 88,21 and 55,26 (spanning exons 16-28 of DCC) was then investigated by genotyping the UK T1D families. The 2-10 haplotype has previously been shown to be positively transmitted to offspring with an autoimmune phenotype (in the UK T1D affected sibpair cohort transmissions to probands are $152 \mathrm{~T}$, $111 \mathrm{NT} ; \% \mathrm{~T}=57.8 ; P=0.01) .{ }^{11}$ The C allele of DCC nt 601 $\mathrm{C} \rightarrow \mathrm{G}$ was over-represented on the 2-10 haplotype $\left(\mathrm{D}^{\prime}\right.$, calculated as described ${ }^{29}$ using parental haplotype frequencies $=0.58)$.

The DCC nt $601 \mathrm{C} \rightarrow \mathrm{G}$ polymorphism was tested for association with autoimmune disease in five independent case-control cohorts from three different populations (one T1D, one RA and three GD). No association of the polymorphism was observed with disease in any of the individual case-control cohorts (Table 1). Hypothesising that the same allele of $\mathrm{nt} 601 \mathrm{C} \rightarrow \mathrm{G}$ may be associated with autoimmunity per se the New Zealand T1D, RA and GD cohorts were combined. Again, no evidence supporting an association of the exon 3 variation with autoimmune disease was obtained (Table 1). Transmission of DCC nt 601 $\mathrm{C} \rightarrow \mathrm{G}$ from heterozygous parents to probands was also tested in the UK affected sibpair T1D cohort. Data were 162 T, 137 NT $(\% \mathrm{~T}=54.2, P=0.15)$. Thus, there was no evidence to support association of DCC nt $601 \mathrm{C} \rightarrow \mathrm{G}$ with T1D in the UK affected sibpair families. However, power for this analysis was only $42 \%$ (CI 18-71\%), $\alpha=0.05$, $\mathrm{OR}=1.21(1.12-1.31)$.

Transmission of common [nt $601 \mathrm{C} \rightarrow \mathrm{G}]-[88,21]-$ $[55,26]$ haplotypes and the G-2-10 haplotype (eighth most frequent) from heterozygous parents to probands was tested in the families (Table 2). The nt $601 \mathrm{C} \rightarrow \mathrm{G}$ polymorphism subdivides the 2-10 haplotype of $[88,21]-$ $[55,26]$ into positively associated (C-2-10, \% $\mathrm{T}=59.1$, $P=0.01)$ and nonassociated $(\mathrm{G}-2-10, \% \mathrm{~T}=37.5, P=0.16)$ haplotypes.

\section{Discussion}

We considered the DCC codon $201 \mathrm{R} \rightarrow \mathrm{G}$ nonconservative substitution as a candidate autoimmune disease aetiological variation. There was a strong a priori reason for undertaking this experiment; in humans and mice the $D C C$ region is strongly implicated in autoimmune disease susceptibility and DCC is a plausible candidate gene for autoimmune disease susceptibility by virtue of its involvement in apoptosis (see Introduction). Despite this, in the present study the nt $601 \mathrm{C} \rightarrow \mathrm{G}$ variation was found not to be associated with autoimmune disease in any of the five case-control cohorts tested (Table 1), nor in the familybased T1D data set. We conclude that the DCC nt $601 \mathrm{C} \rightarrow$ $\mathrm{G}$ variant is not likely to have a major role in autoimmune disease susceptibility when considered as a single polymorphic locus acting independent of other polymorphisms in the DCC region. This conclusion is supported by the presence of the same nt $601 \mathrm{C} \rightarrow \mathrm{G}$ allele on both positively and negatively associated DCC [nt $601 \mathrm{C} \rightarrow \mathrm{G}]-$ $[88,21]-[55,26]$ haplotypes in the UK T1D families. For example, the $\mathrm{C}$ allele is present on the C-2-10 (positively transmitted, $\% \mathrm{~T}=59.1, P=0.01$ ) and C-7-1 (negatively transmitted, $\% \mathrm{~T}=32.8, P=0.009$ ) haplotypes (Table 2 ). 
The case-control association study was adequately powered to test our hypothesis. Reasoning that DCC nt $601 \mathrm{C} \rightarrow \mathrm{G}$ accounts for the previously observed disease association at $D C C^{11}$, it was estimated that the New Zealand autoimmune cohort had $90 \%$ power, and a second independent data set (Birmingham GD) had 68\% power to detect association with disease of a locus with effect equivalent to IDDM6 $(\mathrm{OR}=1.21)$ at the $5 \%$ level of significance. However, substantiation of the lack of association of $D C C$ nt $601 \mathrm{C} \rightarrow \mathrm{G}$ with autoimmune disease will require genotyping in significantly larger cohorts. A study providing $99.5 \%$ power $(\alpha=0.05)$ (using the lower 95\% CI OR estimate for IDDM6 (1.12)) would require 7000 cases and 7000 controls.

Even if it does not have a significant direct role in autoimmune disease susceptibility, it is conceivable that DCC $201 \mathrm{R} \rightarrow \mathrm{G}$ may interact with other polymorphisms in the region to influence protein expression and/or function collectively, thus accounting for at least part of the previously observed linkage and association of DCC with autoimmune disease..$^{5-12}$ To investigate this, the association of haplotypes of DCC with disease will need to be assessed. This will require cohort sizes of thousands of individuals to be of sufficient power to account for the reduced power concomitant with the increased degrees of freedom inherent in the analysis of multiple SNP haplotypes.

In conclusion, the DCC $201 \mathrm{R} \rightarrow \mathrm{G}$ polymorphism does not significantly influence risk of developing the autoimmune diseases tested. Several strategies can be followed to investigate the role of chromosome $18 \mathrm{q} 12-\mathrm{q} 23$ in autoimmune disease further. In humans, we have first concentrated on DCC as an IDDM6 positional candidate. This approach should be continued, focusing in the first instance on the neighbouring centromeric SMAD2, SMAD4 and SMAD7 candidate genes. The SMAD (similar to mothers against decapentaplegic) gene products mediate transforming growth factor- $\beta_{1}$ (TGF- $\beta_{1}$ ) signalling from the cell membrane to the nucleus. Tgf- $\beta_{1}$ signalling is implicated in the control of T-cell homeostasis. ${ }^{30}$ However, the possibility that other polymorphisms within DCC modulate disease risk should not be neglected. Comparative mapping in rodents may be a powerful aid to IDDM6 positional cloning efforts. This would be based on the hypothesis that orthologous chromosome 18 autoimmune disease susceptibility gene(s) exist in human and rodent. It will be necessary to fine map the chromosome 18 autoimmune diabetes loci $\operatorname{Iddm} 3$ (rat) ${ }^{13}$ and $I d d 21$ (mouse $)^{14}$ by constructing and evaluating cumulative diabetes frequency in novel subcongenic strains.

\section{Acknowledgements}

The New Zealand Health Research Council, New Zealand Lottery Grants Board, the University of Otago Dean's Bequest Fund, the
Arthritis Foundation of New Zealand, the RG Bell Charitable Trust, the Juvenile Diabetes Research Foundation, and the Wellcome Trust are thanked for financial support. RJH was supported by a University of Otago Postgraduate Scholarship. Heather Cordell is thanked for advice, John Todd for generously providing access to clinical samples and laboratory facilities and review of the manuscript, Peter Jones (Queen Elizabeth Hospital for Rheumatic Disease and Rehabilitation, Rotorua, NZ) and Vivienne Field (Christchurch Hospital, New Zealand) for recruiting patients, and Richie Poulton (Director of the Dunedin Multidisciplinary Health and Development Study) for collaborating on this project.

\section{References}

1 Gebe JA, Swanson E, Kwok WW: HLA class II peptide-binding and autoimmunity. Tissue Antigens 2002; 59: 78-87.

2 Davies JL, Kawaguchi Y, Bennett ST et al: A genome-wide search for human type 1 diabetes susceptibility genes. Nature 1994; 371: $130-136$.

3 Concannon P, Gogolin-Ewens KJ, Hinds DA et al: A secondgeneration screen of the human genome for susceptibility to insulin-dependent diabetes mellitus. Nat Genet 1998; 19: 292-296.

4 Mein CA, Esposito L, Dunn MG et al: A search for type 1 diabetes susceptibility genes in families from the United Kingdom. Nat Genet 1998; 19: 297-300.

5 Shai R, Quismorio Jr FP, Li L et al: Genome-wide screen for systemic lupus erythematosus susceptibility genes in multiplex families. Hum Mol Genet 1999; 8: 639-644.

6 Jawaheer D, Seldin MF, Amos CI: A genomewide screen in multiplex rheumatoid arthritis families suggests genetic overlap with other autoimmune diseases. Am J Hum Genet 2001; 68: 927-936.

7 Sakai K, Shirasawa S, Ishikawa $\mathrm{N}$ et al: Identification of susceptibility loci for autoimmune thyroid disease to 5q31-q33 and Hashimoto's thyroiditis to 8q23-q24 by multipoint affected sib-pair linkage analysis in Japanese. Hum Mol Genet 2001; 10: 1379-1386.

8 Cornelis F, Faure S, Martinez M et al: New susceptibility locus for rheumatoid arthritis suggested by a genome-wide linkage study. Proc Natl Acad Sci USA 1998; 95: 10746-10750.

9 Lindgren CM, Widén E, Tuomi Tet al: Contribution of known and unknown susceptibility genes to early-onset diabetes in Scandinavia. Diabetes 2002; 51: 1609-1617.

10 Jawaheer D, Seldin MF, Amos CI et al: Screening the genome for rheumatoid arthritis susceptibility gene: a replication study and combined analysis of 512 multicase families. Arthritis Rheum 2003; 48: 906-916.

11 Merriman TR, Cordell HJ, Eaves IA et al: Suggestive evidence for association of human chromosome 18q12-q21 and its orthologue on rat and mouse chromosome 18 with several autoimmune diseases. Diabetes 2001; 50: 184-194.

12 Vaidya B, Imrie H, Perros P et al: Evidence for a new Graves' disease susceptibility locus at chromosome 18q21. Am J Hum Genet 2000; 66: 1710-1714.

13 Klöting I, van den Brandt J, Kuttler B: Genes of SHR rats protect spontaneously diabetic $\mathrm{BB} / \mathrm{OK}$ rats from diabetes: lessons from congenic BB.SHR rat strains.. Biochem Biophys Res Commun 2001; 283: 399-405.

14 Hall RJ, Hollis-Moffatt JE, Merriman ME, Green RA, Baker D, Merriman TR: An autoimmune diabetes locus (Idd21) on mouse chromosome 18. Mamm Genome 2003; 14: 335-339.

15 Mehlen P, Rabizadeh S, Snipas SJ, Assa-Munt N, Salvesen GS, Bredesen DE: The DCC gene product induces apoptosis by a mechanism requiring receptor proteolysis. Nature 1998; 395: 801-804.

16 Corset V, Nguyen-Ba-Charvet KT, Forcet C, Moyse E, Chedotal A, Mehlen P: Netrin-1-mediated axon outgrowth and cAMP 
production requires interaction with adenosine $\mathrm{A} 2 \mathrm{~b}$ receptor. Nature 2000; 407: 747-750.

17 Liu J, Yao F, Wu R et al: Mediation of the DCC apoptotic signal by DIP13 $\alpha$. J Biol Chem 2002; 277: 26281-26285.

18 Forcet C, Ye X, Granger L et al: The dependence receptor DCC (deleted in colorectal cancer) defines an alternative mechanism for caspase activation. Proc Natl Acad Sci 2001; 98: 3416-3421.

19 Kong X-T, Choi SH, Inoue A et al: Expression and mutational analysis of the DCC, DPC4, and MADR2/JV18-1 genes in neuroblastoma. Cancer Res 1997; 57: 3772-3778.

20 Reale MA, Hu G, Zafar AI, Getzenberg RH, Levine SM, Fearon ER: Expression and alternative splicing of the deleted in colorectal cancer (DCC) gene in normal and malignant tissues. Cancer Res 1994; 54: 4493-4501.

21 Arnett FC, Edworthy SM, Bloch DA et al: The American Rheumatism Association 1987 revised criteria for the classification of rheumatoid arthritis. Arthritis Rheum 1988; 31: 315-324.

22 Heward JM, Allahabadia A, Daykin J et al: Linkage disequilibrium between the human leukocyte antigen class II region of the major histocompatibility complex and Graves' disease: replication using a population case-control and family-based study. J Clin Endocrinol Metab 1998; 83: 3394-3397.

23 Mein CA, Barratt BJ, Dunn MG et al: Evaluation of single nucleotide polymorphism typing with invader on PCR amplicons and its automation. Genome Res 2000; 10: 330-443.
24 Risch N, Merikangas K: The future of genetic studies of complex human diseases. Science 1996; 273: 1516-1517.

25 Johnson GC, Esposito L, Barratt BJ et al: Haplotype tagging for the identification of common disease genes. Nat Genet 2001; 29: 233-237.

26 Knapp M: A note on power approximations for the transmission/ disequilibrium test. Am J Hum Genet 1999; 64: 1177-1185.

27 Kong X-T, Choi SH, Bessho F et al: Codon $201^{\text {Gly }}$ polymorphic type of the DCC gene is related to disseminated neuroblastoma. Neoplasia 2001; 3: 267-272.

28 Minami R, Aoyama N, Honsanko Y, Kasuga M, Fujimori T, Maeda S: Codon $201^{\text {Arg/Gly }}$ polymorphism of DCC (deleted in colorectal carcinoma) gene in flat- and polypoid-type colorectal tumors. Dig Dis Sci 1997; 42: 2446-2452.

29 Devlin B, Risch N: A comparison of linkage disequilibrium measures for fine-scale mapping. Genomics 1995; 29: 311-322.

30 Gorelik L, Flavell RA: Transforming growth factor- $\beta$ in T-cell biology. Nat Rev Immunol 2002; 2: 46-53.

31 Dudbridge F: Methods and software for association tests of uncertain haplotypes in case parent trios. Am J Hum Genet 2002; 71 (Suppl.): 569 (Abstract 2338).

32 Spielman R, McGinnis R, Ewens W: Transmission test for linkage disequilibrium: the insulin gene region and insulindependent diabetes mellitus (IDDM). Am J Hum Genet 1993; 52: 506-516. 